\title{
Generation Y as citizens of the European Union
}

\author{
Agnieszka Stanimir \\ Wroclaw University of Economics
}

\begin{abstract}
The aim of the study is to compare the opinions of young Europeans about the European Union. The population survey was a group of people belonging to the Generation Y. This age cohort includes people born in the eighties and nineties of the twentieth century. Generation Y includes the youngest people in the labour market, students or school leavers at the secondary level. Based on data from the Eurobarometr (Standard and Flash), the opinions of Generation Y from the European Union on the importance of the Union for this cohort, the assessments of predicted benefits to its citizens that brings the European Union were compared. Also was analysed what young people understand mean when under being a citizen of the European Union.
\end{abstract}

Keywords: Generation Y, European Union, multivariate statistical analysis

\section{Introduction}

Generation Y, these are people born in the eighties and nineties of the twentieth century. This age cohort includes people who differ in age by 20 years. For this reason, this group is internally very diverse in terms of life, social, and professional experiences and culture. Therefore the study, the results of which are presented in this article, was decided to highlight the age subgroups of: 15-19, 20-24, 25-31(32, 34). Due to the perception of the relationship between private life and work, the Generation Y is significantly different from older generations. Generation Y tends to balance between private life and work. The employment rate of people aged 15-29 from 2000 to 2013 exceeds the unemployment rate, but since 2008 has been declining and unemployment has been rising (see fig. 1, Eurostat data: lfsa_urgan; lfsa_ergan). The observed rate of unemployment in all EU countries for young people was higher than for older people (e.g. those for 2013, see fig. 2, Eurostat data: lfsa_ergan). In 2013 the unemployment rate in Poland and in other European countries was lower for women than for men. The combination of perception of work and private life with the presented employment situation of young people, raises questions about the assessment of young people's views on the economic situation in the European Union. In order to guarantee the European Union a high level of development based on sustainable growth and social inclusion, the strategy Europe 2020 was launched in 2010. In the strategy framework was focused improvement of the situation of young people. Thus, is it interesting how young people feel as members of the European Union and how they assess its actions? The search for an answer to this question was the purpose of the conducted research.

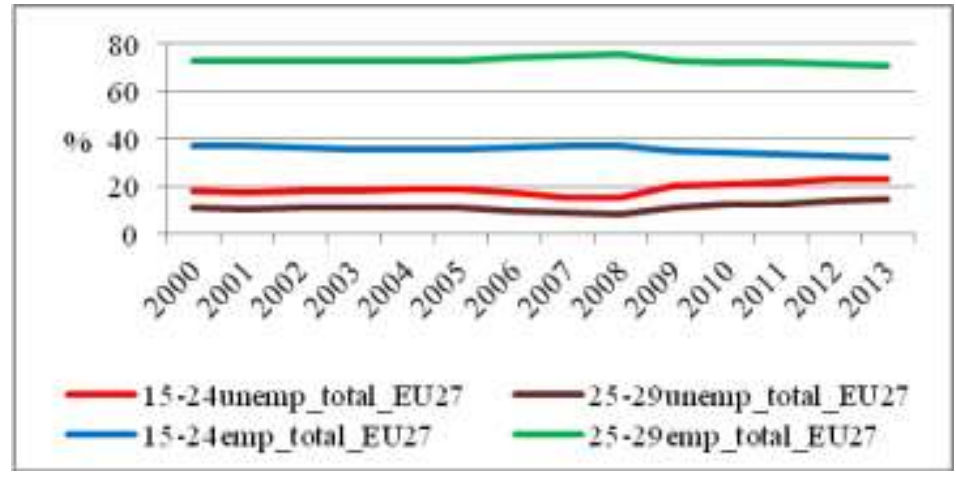

Fig. 1: Employment and unemployment rates in European Union. 


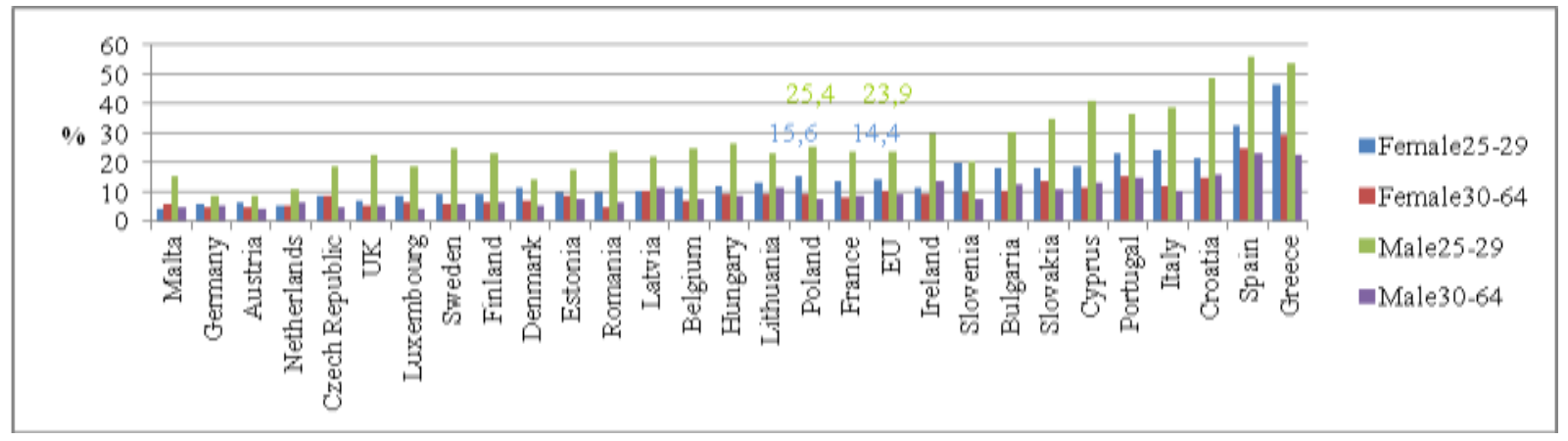

Fig. 2: Unemployment rate in EU countries in 2013.

\section{Generation $Y$}

To understand the necessity of separating of Generation $\mathrm{Y}$ from the total population, some of its characteristics should be pointed out. Generation $Y$ are people who consider the balance between private life and work is very important. It is necessary to understand what values are important to them at their work and in life. Studied Generation Y are very involved in activities that they find interesting and the tasks that can be easily solved. However, they expect constant feedback. If the work gives them more opportunities to realize private interests, then is assessed better. They appreciate the authorities, but their loyalty ends very quickly. Regarding the place of employment, they have more tendency to mobility than the older generation. Due to the very natural use of new technologies, working in international teams in on-line mode is their attribute. Their private lives are strongly influenced by modern technologies. The Internet seems to have been invented just for them. They use it as source of all the information necessary in everyday life (and work). Communicators and social networks replace and simplify verbal communication. Declining verbal communication causes problems in the process of applying for work and its implementation. Social networks are integral characteristics of the Generation Y.

\section{The data}

In order to determine how young Europeans evaluate the European Union, the Eurobarometr data have been used. First the data collected in the survey Young Europeans - a survey among young people aged between 1530 in the European Union were used [2]. This lent the responses to the question below which were examined.

- Q1. I am going to read you a few statements on what the European Union means for people. Please tell me, for each of them, if the European Union means this to you personally or not?

Respondents were allowed to choose one of the answers: 1) A European government; 2) Freedom to travel, study and work anywhere in the EU; 3) A means of improving the economic situation in the EU; 4) A way to protect the rights of citizens; 5) A lot of bureaucracy, a waste of time and money; 6) The risk of losing our cultural identity/diversity.

Next, the data were used from the Eurobarometr survey on Future of Europe [3], [4], [5]. From the Eurobarometr 76.4 and 78.2 the selected question was QA1: Please tell me to what extent you agree or disagree with each of the following statements: You are happy living in your country/ in the UE. However, in the Eurobarometer 81.1 this question did not exist, so answers to the following question D72 were used: Please tell me to what extent you agree or disagree with each of the following statements: My voice counts in the EU/ in my country. From the Eurobarometr 76.4 and 81.1, data, the answers to the literal question were analysed: In your opinion, which two of the following are the main assets of the EU today? Respondents could choose two of the answers: The standard of living of EU citizens (A1), The power of EU's trade (A2), Talents and skills of EU citizens (A3), Quality of infrastructure in the EU (A4), Capacity for research and innovation (A5), The good relationship between the Member States (A6), Commitment to environmental responsibility (A7). In certain of the conducted researches Generation Y was divided into three age groups: 15-19, 20-24, 25-30 (31, $32,34-$ depending on year of study). 


\section{The Results}

In the report on the Eurobarometer 202 survey [1] it was indicated that "overall, young Europeans tend to share a positive image of the European Union (EU) and its future". In 2007, 90\% of young Europeans associated the EU with freedom to travel, study and work anywhere in the EU.

Secondly, they pointed to the EU as a way to protect the rights of citizens and means of improving the economic situation of the Member Countries. It is very important that Generation Y don't perceive the European Union as the risk of losing cultural identity or diversity. These conclusions illustrate the average results obtained from the aggregated data from all the Member States. The countries where most young people pointed to the possibility of improving the economic situation in the EU include Ireland, Poland, Portugal and Slovakia. On the other hand the risk of losing cultural identity or diversity was the biggest concern of young Cypriots. Since the report has not shown whether internally assessments given by Generation Y were consistent (due to the age), correspondence analysis have been carried out taking into account the previously mentioned three age groups.

The results of the analyses are presented in Figures 3 (age 15-19), 4 (age 20-24) and 5 (age 25-30). Correspondence analyses have been performed for the concatenated contingency tables. In all three cases the full dimensional space was $\mathrm{R}^{17}$. The two-dimensional presentation of the results reflects more than $60 \%$ of the real relationship between categories of variables. It is a very good result at such a significant reduction of dimensionality.

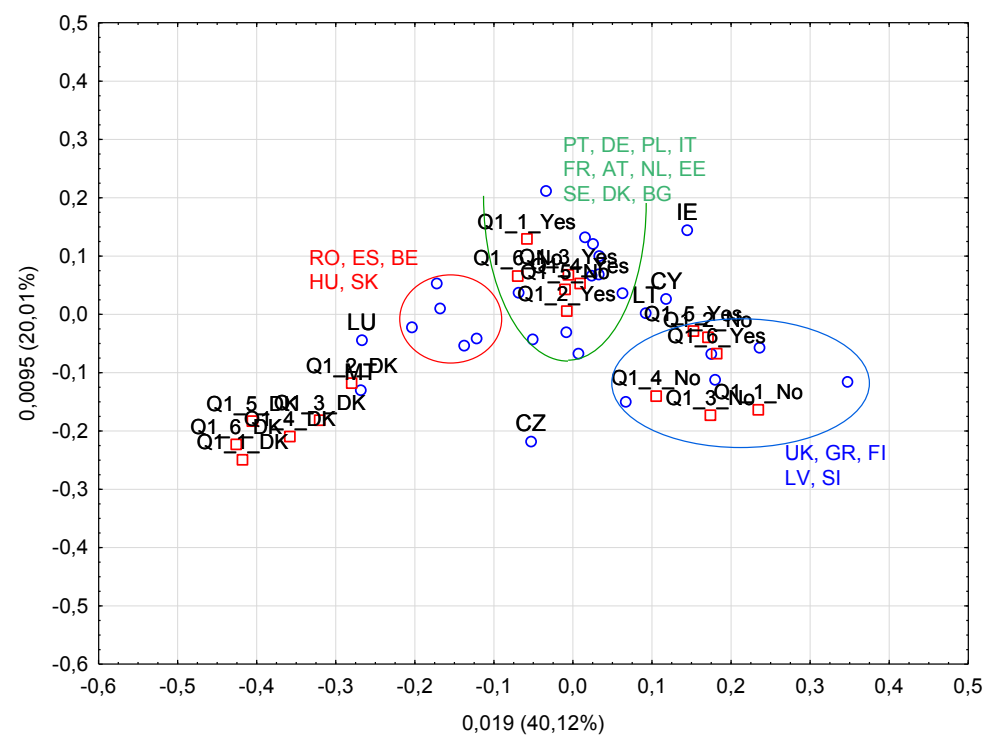

Fig. 3: What the European Union meant for people in age 15-19 in 2007.

For the youngest group of Generation Y, who lived in 2007 in the United Kingdom, Greece, Finland, Latvia and Slovenia the response indicating that the EU gives freedom to travel, study and work anywhere in the EU (Q1_2_Yes), but also associate with a lot of bureaucracy, a waste of time and money (Q1_5_Yes), and that membership in the European Union means losing cultural identity or diversity (Q1_6_Yes) were most characteristic. Moreover, in these countries the youngest person of Gen Y indicated that the EU does not associate with the European Government (Q1_1_No), was not a means of Iiproving the economic situation in the EU (Q1_3_No) and was not a way to protect the rights of citizens (Q1_4_No).

In the another group of countries (Portugal, Germany, Poland, Italy, France, Austria, Netherlands, Estonia, Sweden, Denmark, and Bulgaria), citizens aged 15-19 assessed the European Union very positively. They gave a yes answer to the first four questions, and not to the last two (Q1_1_Yes, Q1_2_Yes, Q1_3_Yes, Q1_4_Yes, Q1_5_No, Q1_6_No). It was typical for Malta, that young people were undecided. 


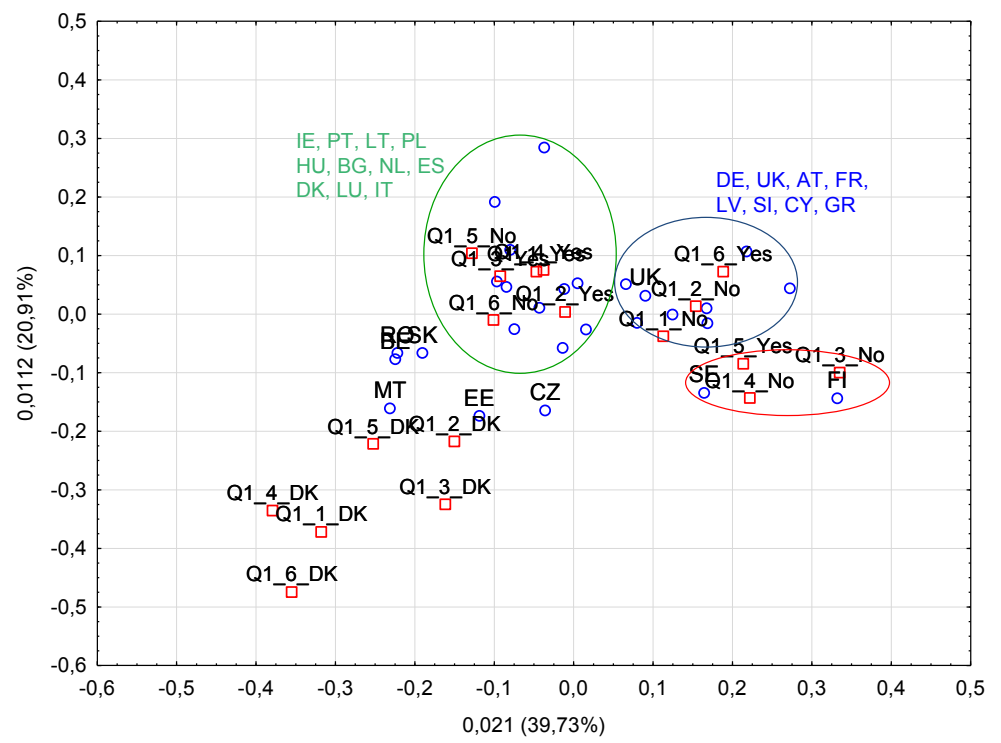

Fig. 4: What the European Union meant for people in age 20-24 in 2007.

In the group aged 20-24, the citizens who evaluate the European Union positively lived in the Ireland, Portugal, Lithuania, Poland, Hungary, Bulgaria, Netherland, Spain, Denmark, Luxembourg and Italy (Q1_1_Yes, Q1_2_Yes, Q1_3_Yes, Q1_4_Yes, Q1_5_No, Q1_6_No). Compared to people aged 15-19 years, this group is smaller. Such countries as Germany, Austria and France have been placed in a group, in which there are still United Kingdom, Slovenia, Cyprus, Latvia, Greece. In these countries, people aged 20-24 from Generation Y most often pointed out that the EU is not associated with the European government (Q1_1_No), freedom to travel, study and work anywhere in the EU (Q1_2_No) but carries the risk of losing cultural identity or diversity (Q1_6_Y). Swedes and Finns aged 20-24 indicated that the European Union does not mean the improvement of the economic situation in the EU (Q1_3_No) and is not a way to protect the rights of citizens (Q1_4_No). Additionally they claimed that the EU is associated with much of bureaucracy, a wasting of time and money (Q1_5_Yes).

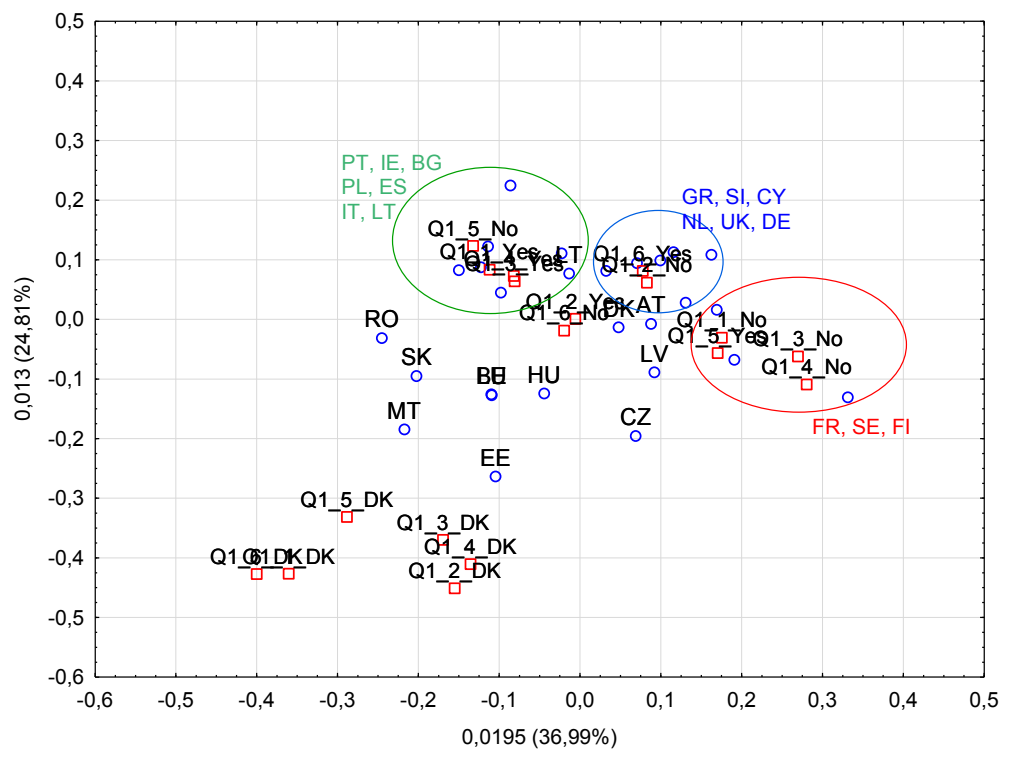

Fig. 5: What the European Union meant for people in age 25-30 in 2007. 
The oldest persons of Generation Y from Portugal, Ireland, Bulgaria, Poland, Spain, Italy and Lithuania assessed almost all the statements about the EU positively (Q1_1_Yes, Q1_3_Yes, Q1_4_Yes, Q1_5_No). Points depicting two positive opinions on the European Union, i.e. Q1_2_Yes, Q1_6_No, lie at the centre, which means that it was equally evaluated by inhabitants of all countries and cannot be considered as characteristic of response of the citizens of any country. Again, Greeks, Slovenians, Cypriots, Danes, English, Germans (Q1_2_No, Q1_6_Yes) and the Finns and Swedes (Q1_5_Yes, Q1_1_No, Q1_3_No, Q1_4_No) assessed the opinions about the European Union negatively.

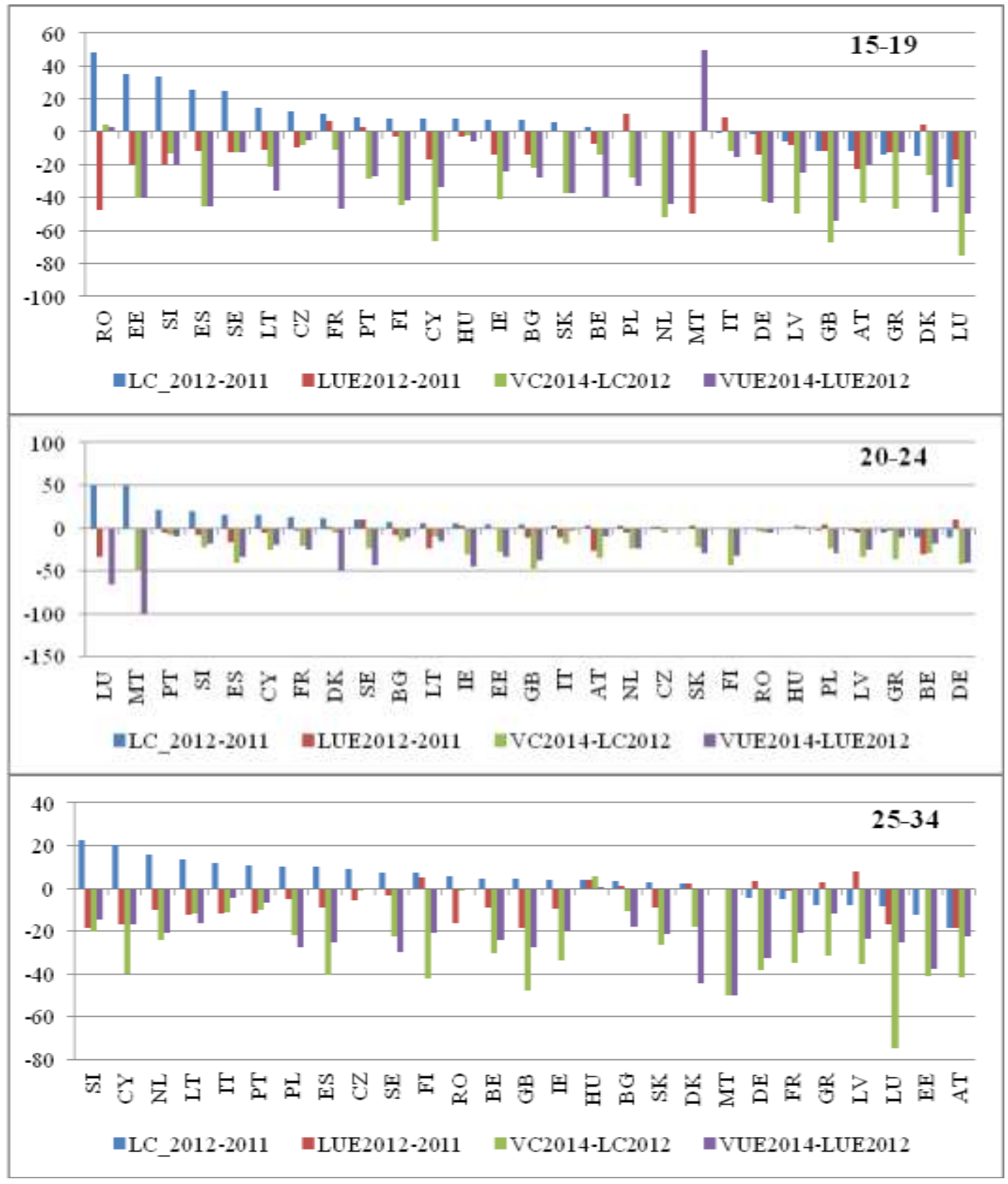

Fig. 6: Happy living in country/EU in 2011, 2012 and My voice counts in the country/EU in 2014 (in percentage points).

Figure 6 shows the differences of rates of people satisfied with life in the country in 2012 to 2011 (LC_20212-2011) and in the EU (LUE2012-2011). Figure 6 contains the differences of the rates of people who in 2014 regarded that their voice counts in the country and in the EU against satisfaction with life in the country and the EU in 2012 (respectively VC2014-LC2012 and VUE2014-LUE2012). It was considered that if the 
respondent believes that their voice counts in the country or in the EU this may reflect his/her satisfaction with life in the country or the EU. The evaluation of satisfaction with life in the EU or in their own country in 2011 and 2012 and importance of statements my voice counts in country were in all three age groups completely different.

Among young people in many countries, happiness with life of inhabitants increased in 2012 compared to 2011 (the most in Romania, Estonia, Slovenia, Spain, Sweden - positive values of LC_20212-2011). In Romania LUE_20212-2011 has a negative value, i.e., in 2011 the residents of Romania aged 15-19 were more satisfied with life in the EU than in 2012. It is worth noting that the proportion of people who believe that their voice counts in the country and the European Union in 2014 was among 15-19 year Romanians higher than satisfaction with life in the country or the EU in 2012.

Satisfaction with life of Poles aged 15-19 were in 2011 and 2012 as similar as in 2012, more people were satisfied living in the EU than in 2011. On the other hand, in Poland were much less people in 2014 who felt that their voice counts in Poland and the EU than those who said in 2012 that they are happy living in Poland and the EU.

Among people aged 20-24 in most countries the share of people satisfied with life in the country or the EU in 2011 and 2012 was similar. By contrast, far less of people in 2014 claimed that their voice counts in the country or the EU than those who were happy to lived in the country or the EU in 2012.

Figure 6 shows the changes in opinion of persons aged 25-34, too. Compared to the previous age group, dissatisfaction with life in the country and the EU in 2012 compared to 2011 in many countries was significantly higher. In addition, participation of persons in most EU countries, who claimed that their voice counts in the country in 2014 was much lower than the proportion of people satisfied with life in the country or the EU in 2012 .

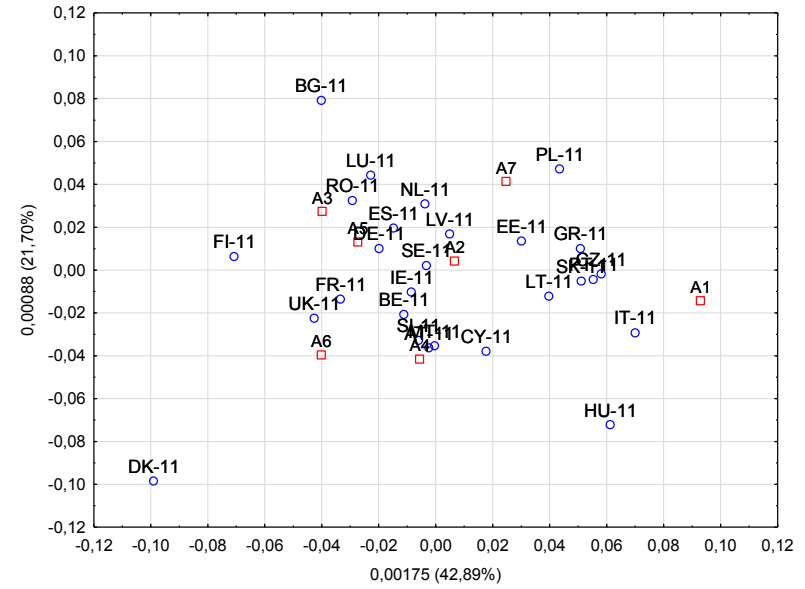

2011

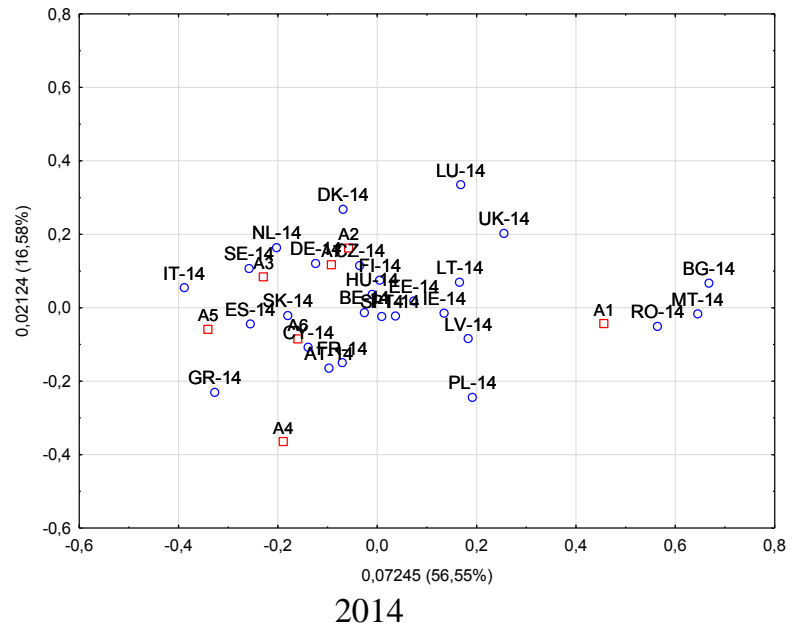

2014

Fig. 7: Main assets of the EU today - opinions of young Europeans in 2011 and 2014.

Analyzing the opinions of young Europeans about the main assets of the European Union in 2011 and 2014 years can be indicated that they are very different (Figure 7).

The standard of living of EU citizens (A1) in 2011 was mentioned as an advantage of the EU in Italy, and in 2014 in Romania, Malta and Bulgaria. The power of the EU's trade (A2) is an advantage of the European Union, which was similarly assessed by Generation Y in all countries analyzed in 2011.

In 2014 in Germany and the Czech Republic the Commitment to environmental responsibility (A7) was similarly evaluated. In 2011, the opportunity to develop talents and skills (A3) were identified as the assets of the EU in Romania, and in 2014 in Sweden and the Netherlands. Quality of infrastructure in the EU (A4) it was advantage of the European Union indicated most often in 2011 by Generation Y from Slovenia, Austria, Malta 
and Cyprus. In 2014 it was impossible to assign this feature to any country. Capacity for research and innovation (A5) in 2011 was an important feature of the EU indicated by young people in Germany and Spain, and in 2014 in Spain, Italy, Greece. The good relationship between the Member States (A6) was indicated as an asset of the EU in 2011 by the inhabitants of the UK and France, while in 2014 the Cypriots and Slovaks. Poles and Estonians chosen as an asset of the EU in 2011 commitment to environmental responsibility (A7).

\section{Conclusions}

During the analyzes was confirmed both the differences between the Generations $\mathrm{Y}$ in European countries and changes in their opinions in analysed periods, but also was indicated that it is difficult to call a Generation $\mathrm{Y}$ as internally homogeneous group of people.

The Member Countries of the European Union were divided into two groups of people aged 15-19: the first with citizens who positively evaluate the EU and the other - opposite. In the subsequent age groups, the number of countries represented by the Generation Y, which were satisfied with life in the EU is smaller. In all age groups (15-19, 20-24, 25-30) in Poland, Portugal and Bulgaria were obtained a positive opinion about the EU in 2007.

Young Europeans were very different in age groups due to satisfaction with life in the country, the European Union and the assessment of the validity of their voice in the country and the EU. Young Poles, regardless of the age groups, in 2007, the European Union evaluated positively. While for young Greeks, British, Slovenians and Finns negative assessment given for statements about the European Union were characteristic.

In the assessment of the positive aspects of the EU in the Member Countries various factors characterizing the opinions of Generation Y in 2011 and 2014 were pointed out.

\section{Acknowledgements}

This study was done as a part of the project "Non-metric multivariate data analysis as a tool for study of adults situation in the context of demographic changes" financed by Narodowe Centrum Nauki (National Science Centre) in Poland. Project number: 2012/05/B/HS4/02499.

\section{References}

[1] Gallup Organization, Youth survey among people aged between 15-30, in the European Union. Analytical Report, Flash Eurobarometer Series \#202, 2007.

[2] European Commission, Flash Eurobarometer 202 (Young Europeans). The GALLUP Organisation, Brussels. GESIS Data Archive, Cologne. ZA4542 Data file Version 1.0.0, 2007, doi:10.4232/1.4542.

[3] European Commission, Eurobarometer 76.4 (2011). TNS OPINION \& SOCIAL, Brussels [Producer]. GESIS Data Archive, Cologne. ZA5596 Data file Version 3.0.0, 2015a, doi:10.4232/1.12181.

[4] European Commission, Brussels, Eurobarometer 78.2 (2012). TNS Opinion, Brussels [producer]. GESIS Data Archive, Cologne. ZA5686 Data file Version 2.0.0, 2015b, doi:10.4232/1.12103

[5] European Commission, Brussels, Eurobarometer 81.1. TNS Opinion, Brussels [producer]. GESIS Data Archive, Cologne. ZA5878 Data file Version 1.0.0, 2015c, doi:10.4232/1.12185 